\title{
Economic aspects of skin cancer management in Eastern Croatia
}

Ivan Miškulin ${ }^{1 *}$, Želimir Orkić2,3, Maja Miškulin³

${ }^{1}$ Faculty of Economics, University of Osijek, Osijek, Croatia, ${ }^{2}$ Clinic for Surgery, University Hospital Osijek, Osijek, Croatia, ${ }^{3}$ Faculty of Medicine, University of Osijek, Osijek, Croatia

\begin{abstract}
Introduction: In the past several decades there has been a substantial increase in the incidence of skin cancers worldwide and Croatia is no exception. The aim of this study was to estimate the financial cost of skin cancer treatment in the Osijek-Baranja County from 2000 to 2009 and to compare it with the cost of a primary prevention campaign organized in the Baranja County.

Methods: We conducted a retrospective analysis of patients with skin cancer in the Baranja County and related health care costs. We designed a potential primary prevention campaign on a County level and calculated the financial expenses of campaign and then compared the results to health care costs from previous years.

Results: The total cost of the treatment involving skin cancer (C43-C44) cases in the Osijek-Baranja County during the 2000-2009 periods was 483,710. The cost of a primary prevention campaign described in this study suggests that the estimated annual cost of a primary prevention campaign on the County level makes around $5.9 \%$ of the annual cost of all the medical treatment involving skin cancer patients in the County, which shows that a planned preventive approach towards the issue of skin cancer in Eastern Croatia is extremely justified and reasonable.
\end{abstract}

Conclusion: The present study reveals the urgent need for the implementation of a primary prevention campaign in Eastern Croatia and puts emphasis on the economic potential of such an approach towards the problem of skin cancer.

Keywords: costs; Croatia; incidence; melanoma; Osijek-Baranja County; primary prevention; skin cancer

\section{INTRODUCTION}

The Osijek-Baranja County is situated in northeastern Croatia and takes up a total area of

\footnotetext{
*Corresponding Author: Ivan Miškulin, Faculty of Economics, University of Osijek, Trg Ljudevita Gaja 7, 31000 Osijek, Croatia. E-mail: miskulin.ivan@gmail.com
}

Submitted: 06 July 2015 / Accepted: 07 September 2015

DOI: http://dx.doi.org/10.17532/jhsci.2015.256
$4.155 \mathrm{~km} 2$, which is $7.3 \%$ of Croatia's territory. It is located on $45^{\circ} 32^{\prime} \mathrm{N}$ and $18^{\circ} 44^{\prime} \mathrm{E}$ latitude and longitude respectively and has a continental climate. It is hot during summer and there are about 1800 to 1900 sunny hours during a one year period (1).

Skin malignancies are among the most common types of human cancer. Three of them, namely basal cell carcinoma (BCC), squamous cell carcinoma (SCC) and malignant melanoma represent about 
95-98\% of all malignant tumors of the skin (1). During the past several decades there has been a substantial increase in the incidence of skin cancers worldwide, as well as in the Croatia (1-3).

Although melanoma accounts for only about 5\% of the total skin cancers, it is the most severe type of cutaneous malignancy (3). Treating melanoma involves substantial medical care costs, while the estimated cost still varies because of the heterogeneity across studies, specifically a study setting, the analyzed population, cost of the approach, and study methods (4).

Non-melanoma skin cancer (NMSC) accounts for the majority of skin cancers in humans. The two major forms of NMSC are BCC and SCC. BCCs represent approximately $70-80 \%$ of all the skin cancers. SCCs are the second most common form of skin cancers (5). Besides BCC and SCC, there are a number of other types of NMSC that are much rarer such as cutaneous lymphomas, adnexal tumors and Merkel cell carcinoma. In total, they comprise only $1-5 \%$ of NMSC (6-8). According to the data of the national social insurance program in the United States, NMSC is the fifth most expensive cancer for health care systems. This increased economic burden is primarily associated with the large number of affected patients and the recurrence rates and not with the cost of treating an individual patient (6). Findings from studies in different countries demonstrate that the medical and economic burden of skin cancer treatment is substantial and increasing. Such findings highlight the importance of skin cancer prevention efforts, which may result in future savings to a healthcare system $(9,10)$.

Given the high incidence rates among young adults and the large number of deaths, skin cancer leads to the loss of a human life (years of potential life lost - YPLL) and indirect costs associated with premature mortality and morbidity have important economic implications $(11,12)$.

Evidence proves that the vast majority of skin cancers are caused by solar ultraviolet radiation (UVR) exposure and this theory is widely accepted $(13,14)$. Both acute and chronic overexposure to the sun, especially early in life, lead to the development of skin cancer which includes melanoma and it is therefore expected that their prevention is achievable through the engagement of sun-protective behaviors (14). On this basis, wearing sun-protective clothing (e.g., long-sleeve shirt, long pants), a broad-brimmed hat and sunglasses, and seeking shade is recommended by health authorities in many Western countries $(14,15)$. A continual use of sunscreens from a broad spectrum and avoidance of artificial tanning equipment are one of the safe measures recommended in protecting the human skin from UVR damage and cancer development $(14,15)$.

Studies have shown that sun-related attitudes and behaviors are influenced by public health campaigns. Additionally, economic study research suggested that the public investment in skin cancer prevention and early detection programs are beneficial for the human health and economy $(9,16)$. However preventive programs for skin cancer, including screening as a potential means for reducing the burden of disease, continues to be underused (17). Consequently, in addition to the pain, suffering and death related to skin cancer, there is also the economic burden that affects society as a whole or the health system.

The aim of this study was to estimate the financial cost of the treatment of skin cancer patients in the Osijek-Baranja County from 2000 to 2009 and to compare those with the costs of a potential primary prevention campaign on the County level. The results of the study will show whether it is financially useful to invest money in a primary skin cancer prevention program.

\section{METHODS}

\section{Data source}

The cohort included all the people with skin cancer (encoded according to the International Statistical Classification of Diseases and Related Health Problems, $10^{\text {th }}$ Revision (ICD-10), i.e. codes C43-C44) who were registered as patients in one of the two hospitals in Osijek-Baranja County from 2000 to 2009 and were registered in the County cancer register within the Institute of Public Health for the Osijek-Baranja County. Namely, in Osijek-Baranja County there are only two Dermatovenerology department (within the two hospitals in the County) in which skin cancer 
be diagnosed and treated. Following the Official Statistic Act in the Republic of Croatia all institutions that manage cancer patients are obliged to report each case of diagnosed cancer by filling out a special form (so called ONKO-form) and sending it to the County cancer register (within the County Institute of Public Health) and County Institutes. They forward these data sources to the Croatian National Cancer Registry (within the Croatian Institute of Public Health). ICD codes used in this study involved all the patients from OsijekBaranja County with malignant melanoma (C43) and all the patients from Osijek-Baranja County with NMSC such as BCC, SCC, and other types of NMSC that are much rarer such as cutaneous lymphomas, adnexal tumors and Merkel cell carcinoma from 2000 to 2009 (C44).

\section{Calculations of skin cancer treatment}

The average cost of each skin cancer entity (melanoma, NMSC) treatment was calculated according to the List of prices of diagnostic and therapeutic procedures in the health care norm issued by the Croatian Institute for Health Insurance in Zagreb 2011, following the prescribed treatment algorithm for melanoma and NMSC in Croatia that included primary and secondary health care. The previously mentioned prescribed treatment algorithm for melanoma and NSMC included the expenses of pathological diagnostics, doctor visits (various family medicine specialists, dermatovenerologists, surgeons, oncologists) and costs of various treatment procedures. We estimated the average cost of one case of melanoma and one case of NMSC and then calculated the cost of treatment of each patient suffering from the aforementioned types of skin cancer. According to this, the average cost of one melanoma treatment in the Osijek-Baranja County has been estimated at $€ 1.382$ (range $€ 1.078$ to $€ 1.686$ depending on the expansion of the disease) and the average cost of one case of NMSC treatment in the Osijek-Baranja County has been estimated at $€ 168$ (range $€ 116$ to $€ 220$ depending on the expansion of the disease). It is important to emphasize that the above mentioned costs are estimations, based on the prices of the procedures and diagnoses that were identical in all the hospitals in Croatia. However, there could still be some variability because we cannot be sure that each provider fully followed the prescribed algorithm for skin cancers treatment in Croatia and that each patient cooperated and complied with the steps within the algorithm.

\section{Calculation of the cost of the primary prevention campaign on the County level}

According to the 2011 census, the Osijek-Baranja County has a total population of 304899 with 110921 households (18). According to the Registry of Health Care Workers in Croatia, recorded within the Croatian National Institute of Public Health, there are 192 general practitioners working in the primary health care setting, 17 pediatricians and 11 specialists of school and university medicine in the Osijek-Baranja County (19). It is recommended that the primary prevention campaigns target the specific groups at risk; mostly adolescents, children and young parents (20). Accordingly, one can say that the primary health care workers (general practitioners, pediatricians and specialists of school and university medicine) should be the key stones of the primary prevention campaign designed to include the vulnerable groups within the OsijekBaranja County. In this sense one can plan the ten year primary prevention campaign that will consist of written materials distributed to all the County households every tree year (during second, fifth and eighth year of the campaign), individual counseling and educational lectures provided by the general practitioners, pediatricians and specialists of school and university medicine working in the field. They can work only after they have been given the appropriate information on the campaign and this will occur in seminars that will be held twice during the ten year campaign (during first and sixth year of the campaign). The individual counseling and the educational lectures will be held continuously during each of ten year of the campaign. The average costs of one written material was based on the average design, print and distribution costs available from providers of such services in the County and the required number of those written materials was based on the number of households in OsijekBaranja County according to the 2011 census. The extra expenses of such a campaign involve the cost of the education of primary health care workers who are in charge of the individual counseling and the 
educational lectures among the County population because one of the key assignments' of these medical specialists is in fact health promotion activities. Taking everything that has been mentioned into account the total costs of such a primary prevention campaign will be around $€ 47,000$ and with this type of campaign one can cover the whole County population and most importantly all preschool children, all school children and the majority of the student population, which are considered as vulnerable groups. Taking into account the analysis and the overall costs of the campaign one can see that the written material costs $€ 0.10$ (per piece) and we need 332763 of these to cover all County households every tree years, which results in $€ 33,276$ as the overall cost for written materials. Besides that we need $€ 13,724$ for two educational courses which provide additional education for primary health care workers who are in charge of individual counseling and educational lectures among the County population.

\section{Statistical analysis}

Statistical analysis included data obtained by the retrospective analysis of all skin cancer patients in the County during 2000-2009 period as well as the calculated health care costs for all of these cases. Upon confirming normality of data distribution by Kolmogorov-Smirnov test, the data was analyzed using descriptive statistics. Mean values of continuous variables that are not distributed normally were expressed as median and range. Statistical analysis was done by the SPSS Statistical Package for Windows, version 13.0 (SPSS Inc., Chicago, IL, USA).

\section{RESULTS}

From 2000 to 2009 there were 253 people registered and diagnosed with melanoma (C430-C439) and 798 people registered with NMSC (C440-C449), leading to a total number of 1051 people registered with the skin cancers (C43-C44) in the OsijekBaranja County. According to this, the median number of the people registered with the skin cancer (C43-C44) in the Osijek-Baranja County during each year was 109 people (range 61-141 people); the median number of people registered with melanoma
(C430-C439) in the Osijek-Baranja County during each year was 28 people (range 16-31 people); the median number of people registered with NMSC (C440-C449) in the Osijek-Baranja County during each year was 88 people (range 37-110 people) (Table 1).

From 2000 to 2009 the total cost of all melanoma (C430-C439) treatment cases in the OsijekBaranja county was $€ 349.646$; the total costs of all the NMSC (C440-C449) treatment cases was $€ 134.064$, leading to a total cost which includes all types of skin cancer (C43-C44) treatment cases and the cost is $€ 483.710$ (Table 2). According to the presented data, the median value of the cost of all skin cancer (C43-C44) treatment cases in the OsijekBaranja County during each year was $€ 49.402$ (range $€ 37.400-€ 61.322$ ); the median value of the cost of all melanoma (C430-C439) treatment cases in the Osijek-Baranja County during each year was $€ 38.696$ (range €22.112-€42.842); the median value of costs of all the NMSC (C440-C449) treatment cases in the Osijek-Baranja County during each year was €14.700 (range €6.216-€18.480).

In order to provide more accurate estimations on skin cancer (C43-C44) treatment cases, we calculated the present value (PV) of all costs using the economic formula:

$$
\mathrm{PV}=\frac{\text { Future costs }}{(1+\text { discount rate })^{\text {years }}}(21)
$$

The discount rate reflects the depreciation of money and all material values over time. It accounts for the lost opportunity of future earnings through present investment (21). For instance, if one assumes an annual discount rate of $2 \%$, the present value of calculated costs of C430-439 skin cancer treatment in the year 2000 is $€ 24.644$ today.

The total cost of the previously described primary prevention campaign will be around $€ 47.000$; the median value of the cost of such a primary prevention campaign during each year will be $€ 2.934$ (range $€ 0-€ 11.832$ ). When one sees the estimated annual cost of the primary prevention campaign and the annual cost of all skin cancer treatment cases during one year (2.934/49.402) it is evident that the estimated annual costs of the primary prevention campaign make around $5.9 \%$ of the annual 
TABLE 1. People registered with skin cancer (C43-C44) in the Osijek-Baranja county during 2000-2009 period

\begin{tabular}{|c|c|c|c|c|c|c|c|c|c|c|c|}
\hline \multirow[t]{2}{*}{ ICD-10 } & \multicolumn{10}{|c|}{ Year/number of registered cancer cases $(\mathrm{N})$} & \multirow[t]{2}{*}{ Total } \\
\hline & 2000 & 2001 & 2002 & 2003 & 2004 & 2005 & 2006 & 2007 & 2008 & 2009 & \\
\hline C430-C439 & 24 & 20 & 29 & 29 & 16 & 27 & 16 & 30 & 31 & 31 & 253 \\
\hline C440-C449 & 37 & 64 & 52 & 59 & 91 & 84 & 94 & 110 & 97 & 110 & 798 \\
\hline Total & 61 & 84 & 81 & 88 & 107 & 111 & 110 & 140 & 128 & 141 & 1051 \\
\hline
\end{tabular}

TABLE 2. Calculated costs of skin cancer (C43-C44) treatment in the Osijek-Baranja county from 2000 to 2009

\begin{tabular}{lccccccccccc}
\hline ICD-10 & \multicolumn{8}{c}{ Year/calculated costs of skin cancer treatment $(€)$} & Total \\
\cline { 2 - 10 } & 2000 & 2001 & 2002 & 2003 & 2004 & 2005 & 2006 & 2007 & 2008 & 2009 & \\
\hline C430-C439 & 33.168 & 27.640 & 40.078 & 40.078 & 22.112 & 37.314 & 22.112 & 41.460 & 42.842 & 42.842 & 349.646 \\
PV costs for C430-C439 & 24.644 & 20.948 & 30.982 & 31.601 & 17.784 & 30.610 & 18.502 & 35.386 & 37.297 & 38.042 & 285.796 \\
C440-C449 & 6.216 & 10.752 & 8.736 & 9.912 & 15.288 & 14.112 & 15.792 & 18.480 & 16.296 & 18.480 & 134.064 \\
PV costs for C430-C439 & 4.619 & 8.149 & 6.753 & 7.816 & 12.296 & 11.577 & 13.214 & 15.773 & 14.187 & 16.410 & 110.791 \\
Total & 39.384 & 38.392 & 48.814 & 49.990 & 37.400 & 51.426 & 37.904 & 59.940 & 59.138 & 61.322 & 483.710 \\
PV Total costs & 29.263 & 29.096 & 37.735 & 39.417 & 30.079 & 42.187 & 31.716 & 51.158 & 51.483 & 54.452 & 396.587 \\
\hline
\end{tabular}

PV-present value

costs of all the skin cancer treatment cases in the Osijek-Baranja County.

\section{DISCUSSION}

In Croatia, the incidence of the malignant melanoma has increased $337 \%$ in the last 30 years (from 1977 to 2006). The mortality rate from malignant melanoma throughout the same period has risen $338 \%$ (22). In the Osijek-Baranja County, the incidence of malignant melanoma has risen $13 \%$ in seven years (2000-2006), while the mortality rate has risen by $18 \%$ in nine years (2000-2008) (3). Until 2003, the incidence of the major NMSC (BCC and SCC) and the other NMSC in Croatia was not reported due to restrictions and obstacles in finding resources $(1,23)$ but the first report on the epidemiological features of the SCC pointed out that the incidence of the SCC in Osijek-Baranja County is significant and it is and will be a public health burden due to the morbidity and the mortality rates (1). Considering all these facts it is of great urgency to find adequate ways of dealing and preventing skin cancer, not only to avoid significant human suffering, but also to avoid significant economic expenses.

According to our findings, there has been no attempt to estimate the cost of skin cancer treatment in the Osijek-Baranja County or to estimate the cost of the primary prevention campaign that deals with the prevention of skin cancers in the region. The results of our study have shown that the total cost of all the skin cancers (C43-C44) treatment cases in the Osijek-Baranja County from 2000 to 2009 were $€ 483.710$, and according to a steady increase in the incidence of the malignant melanoma and the NMSC $(1,3)$ in the region one can justifiably conclude that these expanses will also grow in the coming years. The costs of the primary prevention campaign described in our study suggest that the estimated annual costs of the primary prevention campaign on the County level make around 5.9\% of the annual costs of all the skin cancer treatment cases in the Osijek-Baranja County which shows that a planned preventive approach towards the issue of skin cancer in Eastern Croatia is extremely justified and reasonable. The advantages of such a preventive approach to the problem of skin cancer are reflected in the fact that studies elsewhere in the world have confirmed how the primary prevention campaigns have successfully increased the awareness of the people about the potential harm that comes from overexposure to the sun (24). Studies have further confirmed how primary prevention and sun protection may reduce the incidence of skin cancer for those at risk of developing skin cancer $(25,26)$. Other studies have also pointed out that children and adolescents are target groups and primary preventive efforts are necessary. Preventing damage to the skin caused by UV radiation might have the 
greatest skin cancer preventive effect. Teaching children about sun protection may lead to them having and nurturing a healthy attitude (27-30). It has been estimated that $78 \%$ of accumulated sun exposure and damage can be eliminated if children use sunscreen continuously when outdoors, from infancy to 18 years (24). Adolescents were described as being reluctant to use sunscreen protection and having less favorable attitudes towards sun protection compared to children. Special programs designed for this age group help to increase their sun protective behavior and there is a necessity for such programs $(24,28)$. Considering the application of sunscreen as one of the primary prevention activities in the last ten years there were certain controversies. Namely, the sunscreen is effective in reducing the solar keratosis (31) and sunburn (32) but several epidemiological studies have pointed to the increase in skin damage among sunscreen users, due to the fact that those people who use sunscreen stay longer under the sun (33-36). Even before these results were published, sunscreen has been recommended as an adjunct to other forms of protection and not a substitute for it (24). Sunscreen was recommended as an alternative means of protection for situations where clothing may not be desirable or appropriate $(32,37)$. Current guidelines about primary prevention of skin cancer still feature three main messages introduced 20 years ago in the 'Slip! Slop! Slap!' campaigns $(38,39)$. These include protective clothing, correctly applied and reapplied sunscreen, and a wide-brimmed hat. Additionally, sun exposure during midday hours should be avoided whenever possible $(14,20,24)$. The possibilities of skin cancer prevention through prevention programs in Europe are confirmed by De Vries et al. They emphasize that a combination of different preventive interventions used to protect the population in Europe fully against UV radiation may avoid 30\% and more future cases of SCC, BCC and malignant melanoma, in the year 2050 (40). Today, there are only few studies that have assessed the cost effectiveness of the preventive programs for skin cancer in the world and all of them had demonstrated that a comprehensive health promotion campaign aimed at skin cancer might constitute an excellent value for money from a societal perspective $(9,14,41,42)$. Despite this, the effectiveness is still an important issue because it is well known that long-term consistency and continuity of effort at all social levels is necessary for primary prevention programs to be effective.

\section{CONCLUSION}

The present study reveals the urgent need for the implementation of the primary prevention campaign in Eastern Croatia and also emphasizes the economic potential of such an approach to the skin cancer problem. The similarly designed preventive campaigns that had been implemented elsewhere in the world showed the effectiveness of such an approach not only in terms of increased awareness of skin cancer prevention, but also importantly in terms of improving the sun protective behavior and reducing the skin cancer rates. Bearing in mind that prevention is a long-term issue and will require a major change in the attitude and the behavior of the population and based on the estimates presented in our study one can conclude that the potential health benefits and costs saved from an effective preventive program are significant and cannot be neglected but they must be taken into an account when planning health care programs in the near future.

\section{CONFLICT OF INTEREST}

The authors declare no conflict of interest.

\section{REFERENCES}

1. Kraljik N, Rosso M, Ageel A, Šepić T, Gmajnić R. The Incidence of Skin Squamous Cell Carcinoma in Osijek-Baranja County - An Epidemiological Study. Coll. Antropol. 2011;35(Suppl 2):77-80.

2. Materljan E, Zamolo G, Petković M, Ivošević D, Popović, B, Materljan M, et al. Malignant Skin Melanoma in Croatia. Coll. Antropol. 2009;33(4):1363-8.

3. Kraljik N, Rosso M, Šepić T, Maleš J, Vranješ Ž, Kondža G. Epidemiologic Data of Malignant Melanoma in Osijek-Baranya County (Eastern Croatia) During the Period of 2000-2008. Coll. Antropol. 2010;34(Suppl 2):39-43.

4. Guy GP Jr, Ekwueme DU, Tangka FK, Richardson LC. Melanoma treatment costs: a systematic review of the literature, 1990-2011. Am. J. Prev. Med. 2012;43(5):537-45. doi: 10.1016/j.amepre.2012.07.031.

5. American Cancer Society. Skin cancer: basal and squamous cell. Atlanta: American Cancer Society; 2008.

6. Gualdi G, Monari P, Apalla Z, Lallas A. Surgical treatment of basal cell carcinoma and squamous cell carcinoma. G. Ital. Dermatol. Venereol. 2015;150(4):435-47.

7. Canadian Partnership against Cancer. The economic burden of skin cancer in Canada: current and projected. Toronto: Canadian Partnership against Cancer; 2010. 
8. Šustić N, Biljan D, Orkić Ž, Lizatović D, Milas-Ahić J. Merkel cell carcinoma: case report. Coll. Antropol. 2010;34(Suppl 2):291-3.

9. Gordon LG, Rowell D. Health system costs of skin cancer and cost-effectiveness of skin cancer prevention and screening: a systematic review. Eur. J. Cancer. Prev. 2015;24(2):141-9. doi: 10.1097/CEJ.0000000000000056.

10. Guy GP Jr, Machlin SR, Ekwueme DU, Yabroff KR. Prevalence and costs of skin cancer treatment in the U.S., 2002-2006 and 2007-2011. Am. J. Prev. Med. 2015;48(2):183-7. doi: 10.1016/j.amepre.2014.08.036.

11. Guy GP, Ekwueme DU. Years of potential life lost and indirect costs of melanoma and non-melanoma skin cancer: a systematic review of the literature. Pharmacoeconomics. 2011;29(10):863-74. doi: 10.2165/11589300-000000000-00000.

12. Miškulin I, Ambroš I. Productivity losses from road traffic deaths in Croatia. In: Jautz U, Cini V, editors. Interdisciplinary Management Research X. Osijek: Josip Juraj Strosmayer University of Osijek, Faculty of Economics in Osijek; 2014 ${ }^{\text {th }}$ p. $745-54$.

13. Young C. Solar ultraviolet radiation and skin cancer. Occup. Med. (Lond). 2009;59:82-8. http://dx.doi.org/10.1093/occmed/kqn170.

14. Hirst NG, Gordon LG, Scuffham PA, Green AC. Lifetime cost-effectiveness of skin cancer prevention through promotion of daily sunscreen use. Value. Health. 2012;15(2):261-8. doi: 10.1016/j.jval.2011.10.009.

15. Miškulin M. Physical environmental factors (in Croatian). In: Puntarić D, Miškulin M, Bošnir J. Zdravstvena ekologija. Zagreb: Medicinska naklada; $2012^{\text {th }}$ p. $157-88$.

16. Shih ST, Carter R, Sinclair C, Mihalopoulos C, Vos T. Economic evaluation of skin cancer prevention in Australia. Prev. Med. 2009;49(5):449-53. doi: 10.1016/j.ypmed.2009.09.008

17. Losina E, Walensky RP, GellerA, Beddingfield FC $3^{\text {rd }}$, Wolf LL, Gilchrest BA, et al. Visual screening for malignant melanoma: a cost-effectiveness analysis. Arch. Dermatol. 2007;143(1):21-8. doi: 10.1001/archderm.143.1.21.

18. Croatian Bureau of Statistics. Census of population, households and dwellings 2011, first results by settlements. Zagreb: Croatian Bureau of Statistics; 2011.

19. Croatian National Institute of Public Health. Register of health care workers. Zagreb: Croatian National Institute of Public Health; 2013

20. Šitum M, Vurnek Živković M, Dediol I, Zeljko Penavić J, Šimić D. Knowledge and Attitudes towards Sun Protection in Croatia. Coll. Antropol. 2010;34(Suppl 1):141-6.

21. Sonnenberg A, Inadomi JM. Review article: medical decision models of Helicobacter pylori therapy to prevent gastric cancer. Aliment Pharmacol Ther, 1998;12(Suppl. 1):111-21. http://dx.doi. org/10.1111/j.1365-2036.1998.00001.x

22. Croatian National Institute of Public Health, Croatian National Cancer Registry. (1983-2008). Cancer incidence in Croatia. Zagreb: Croatian National Institute of Public Health, 1983-2008.

23. Lipozenčić J, Celić D, Strnad M, Jurakić Tončić R, Pašić A, Radoš J, et al. Skin Cancers in Croatia, 2003-2005: Epidemiological Study. Coll. Antropol. 2010;34(3):865-9.

24. Stanton WR, Janda M, Baade PD, Anderson P. Primary prevention of skin cancer: a review of sun protection in Australia and internationally. Health. Promot. Int. 2004;19(3):369-78. doi: 10.1093/heapro/dah310.

25. Staples M, Marks R, Giles G. Trends in the incidence of non-melanocytic skin cancer (NMSC) treated in Australia 1985-1995: are primary prevention programs starting to have an effect? Int. J. Cancer. 1998;78(2):144-8. doi: 10.1002/(SICI)1097-0215(19981005)78:2<144:AID-IJC3>3.0.CO;2-Z.
26. Giles GG, Thursfield V. Trends in skin cancer in Australia. Cancer. Forum. 1996;20(Special Edition):188-191.

27. Glanz K, Lew RA, Song V, Cook VA. (1999). Factors associated with skin cancer prevention practices in a multiethnic population. Health. Educ. Behav. 1999;26(3):344-59. doi: 10.1177/109019819902600305.

28. Graffunder CM, Wyatt SW, Bewerse B, Hall I, Reilley B, Lee-Pethel R. Skin cancer prevention: the problem, responses, and lessons learned. Health. Educ. Behav. 1999;26(3):308-16. doi: 10.1177/109019819902600303.

29. Marks R. Two decades of the public health approach to skin cancer control in Australia: why, how and where are we now? Australas. J. Dermatol. 1999;40(1):1-5. doi: 10.1046/j.1440-0960.1999.00307.x.

30. Stöver LA, Hinrichs B, Petzold U, Kuhlmei H, Baumgart J, Parpart C, et al. Getting in early: primary skin cancer prevention at 55 German kindergartens. Br. J. Dermatol. 2012;167(Suppl 2):63-9. doi: 10.1111/j.1365-2133.2012.11088.x.

31. Thompson SC, Jolley D, Marks R. Reduction of solar keratoses by regular sunscreen use. N. Engl. J. Med. 1993:329(16):1147-51. doi: 10.1056/ NEJM199310143291602.

32. Pruim B, Green A. Photobiological aspects of sunscreen re-application. Australas. J. Dermatol. 1999;40(1):14-8. doi: 10.1046/j. 1440-0960.1999.00309.x.

33. Autier $P$, Doré JF. Influence of sun exposures during childhood and during adulthood on melanoma risk. EPIMEL and EORTC Melanoma Cooperative Group. European Organisation for Research and Treatment of Cancer. Int. J. Cancer. 1998;77(4):533-7. doi: 10.1002/ (SICI)1097-0215(19980812)77:4<533:AID-IJC10>3.0.CO;2-7.

34. Autier P, Doré JF, Cattaruzza MS, Renard F, Luther H, Gentiloni-Silveri F, et al. Sunscreen use, wearing clothes, and number of nevi in 6- to 7-year-old European children. European Organization for Research and Treatment of Cancer Melanoma Cooperative Group. J. Natl. Cancer. Inst. 1998;90(24):1873-80. doi: 10.1093/jnci/90.24.1873.

35. Autier P, Doré JF, Négrier S, Liénard D, Panizzon R, Lejeune FJ, et al. Sunscreen use and duration of sun exposure: a double-blind, randomized trial. J. Natl. Cancer. Inst. 1999;91(15):1304-9. doi: 10.1093/jnci/91.15.1304.

36. Robinson JK, Rigel DS, Amonette RA. Summertime sun protection used by adults for their children. J. Am. Acad. Dermatol. 2000;42(5Pt1):746-53. doi: $10.1067 / \mathrm{mjd} .2000 .103984$.

37. Turner M. Sun safety: avoiding noonday sun, wearing protective clothing, and the use of sunscreen. J. Natl. Cancer. Inst. 1998;90(24):1854-5. doi: 10.1093/jnci/90.24.1854.

38. Weinstock MA. Sunscreen. Curr. Opin. Oncol. 2000;12(2):159-162. doi: 10.1097/00001622-200003000-00011.

39. Montague M, Borland R, Sinclair C. Slip! Slop! Slap! and SunSmart, 1980-2000: Skin cancer control and 20 years of population-based campaigning. Health. Educ. Behav. 2001;28(3):290-305. doi: 10.1177/109019810102800304.

40. De Vries E, Arnold M, Altsitsiadis E, Trakatelli M, Hinrichs B, Stockfleth E, et al.; EPIDERM Group. Potential impact of interventions resulting in reduced exposure to ultraviolet (UV) radiation (UVA and UVB) on skin cancer incidence in four European countries, 2010-2050. Br. J. Dermatol. 2012;167(Suppl 2):53-62. doi: 10.1111/j.1365-2133.2012.11087.x.

41. Carter R, Marks R, Hill D. Could a national skin cancer primary prevention campaign in Australia be worthwhile?: An economic perspective. Health. Promot. Int. 1999;14(1):73-82. doi: 10.1093/heapro/14.1.73.

42. Sinclair C, Foley P. Skin cancer prevention in Australia. Br. J. Dermatol. 2009;161(Suppl 3):116-23. doi: 10.1111/j.1365-2133.2009.09459.x. 